\title{
RUSSIA'S REAL SECTOR OF THE ECONOMY IN H1 2015: FACTORS AND TRENDS
}

\author{
O.Izryadnova
}

In $\mathrm{H} 12015$, business activities in the Russian economy were determined by weakening of the external and internal demand. In $\mathrm{H1}$ 2015, a decrease of 5.4\% and 8.0\% in investments in capital assets and the volume of the retail trade, respectively, as compared to the respective period of the previous year produced a negative effect on the domestic market. In Q2, the situation became more complicated due to a greater slump in the industry to $4.9 \%$, including the manufacturing industry to $5.1 \%$ as compared to the indices of the previous year.

A drop in real wages and salaries with a consolidating trend of growth in general and registered unemployment is an alarming factor.

During the past three years, the growth rates of the industrial production, retail trade volume and building and investment activities have been falling. A decrease in the physical volume of output by the base types of economic activities as compared to the previous year was registered for the first time after the 2008-2009 crisis only in H1 2015. It is to be noted that a downward trend of output consolidated in Q2 as compared to Q1. If in 2014 volatility of indices of investment activities was partially compensated by positive dynamics of the volume of retail trade and industrial and agricultural production, the situation in $\mathrm{H} 12015$ became more complicated due to a simultaneous decrease in the extent of consumer and investment demand with a slump of industrial production becoming more dramatic. In $\mathrm{H} 12015$, the industrial production index, the volume of jobs in building and the retail trade volume amounted to $97.3 \%, 94.6 \%$ and $92.0 \%$, respectively, as compared to the respective period of the previous year. A drop in output in the real sector of the economy resulted in reduction of demand on infrastructure services: freight turnover fell by $2.3 \%$ as compared to $\mathrm{H} 1$
2014. It is to be noted that only a $2.9 \%$ growth in agricultural produce as compared to $\mathrm{H} 12014$ had a positive effect on the economic dynamics in 2015 as a year before.

According to the preliminary data, in $\mathrm{H} 12015$ GDP fell by $3.4 \%$ with consolidation of a slump from

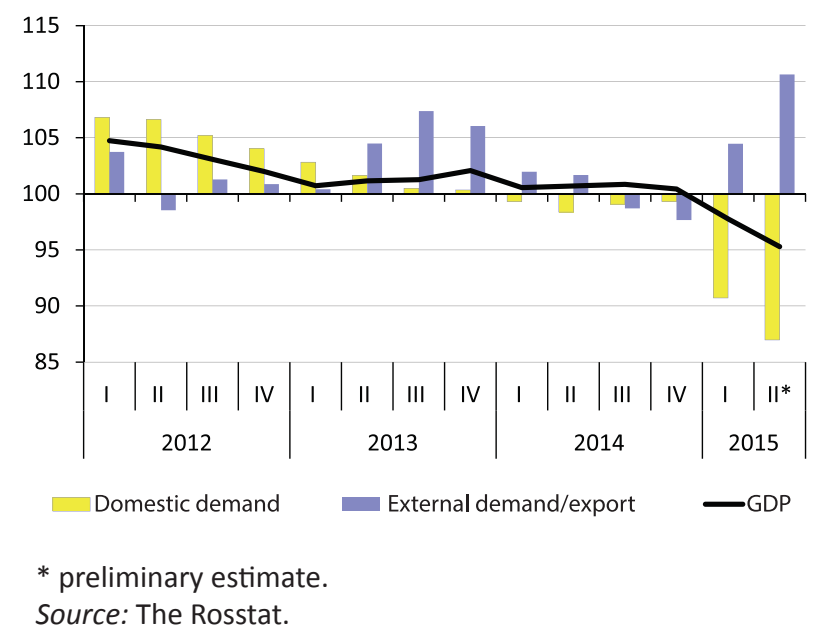

Fig. 1. Dynamics of GDP by the component in the 2012-2015 period as \% of the respective quarter of the previous year

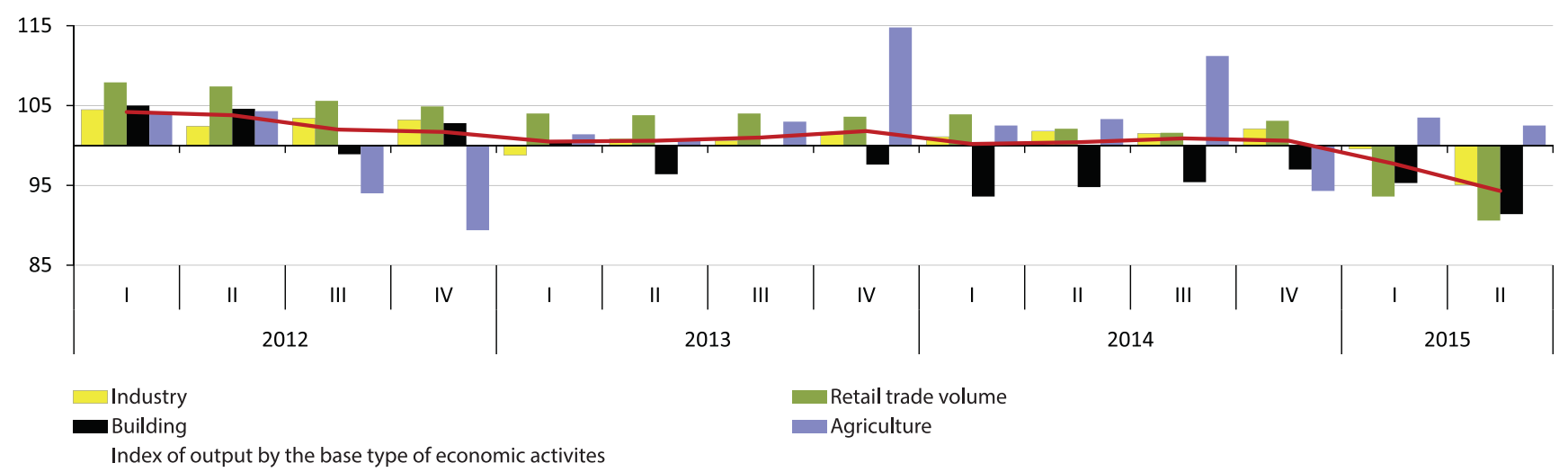

Source: The Rosstat.

Fig. 2. Dynamics of base types of economic activates in the 2012-2015 period as \% of the respective quarter of the previous year 
$2.2 \%$ in Q1 to $4.3 \%$ in Q2 against the respective indices of the previous year. In 2015 the negative impact of a trend of narrowing of domestic demand - which trend has prevailed during the past six quarters - has become stronger. A decrease in GDP as regards utilization is related to a drop in the gross accumulation of capital assets, decrease in inventories and cuts in spendings on ultimate consumption by households.

With the existing economic model, the net export whose contribution was determined by prevalence of growth in revenues of export-orientated industries (calculated on the basis of the methods of the system of national accounts (SNA)) on the one side and a dramatic drop in the dynamics and share of the import in GDP on the other side had a positive effect on the economic dynamics in H1 2015. So, a compensating effect from a drop in import permitted to smooth over the shock caused by worsening of foreign trade conditions.

The situation in $\mathrm{H} 12015$ became more complicated due to a more dramatic drop in domestic demand. Depreciation of the ruble, a high level of the debt of households and speed-up of the rate of inflation resulted in a drop in revenues of households and slowdown of consumption. In H1 2015, ultimate consumption of households and investments in capital assets fell by $8.1 \%$ and $5.4 \%$, respectively, as compared to the indices of the previous year. Higher slump of consumer demand was justified by a drop in households' incomes for three quarters running. In H1 2015, households' real incomes, real wages and the real size of pensions granted amounted to $96.9 \%$, 91.5\% and $95.8 \%$ (January-May), respectively, as compared to the respective period of the previous year. Households reacted to a change in the level of their income by cutting demand by $7.7 \%$ and $8.3 \%$ on food products and non-food products, respectively, as compared to $\mathrm{H} 12014$. It is to be noted that the quarterly dynamics of the current year illustrates consolidation of the trend of reduction of sales turnover by the segment of the consumer market. There is a change in consumer behavior of households: they tend more to saving with a reduction of the share of expenditures on current consumption. In January-May 2015, the share of savings in households' cash income amounted to $13.5 \%$ against $4.4 \%$ a year before. Indexation of regulated tariffs on housing and utilities services in $\mathrm{H} 22015$ with the last year situation taken into account will probably result in further weakening of the dynamics of the retail trade volume.

The main factors behind slowdown of investment processes are still limitations on borrowing of credit

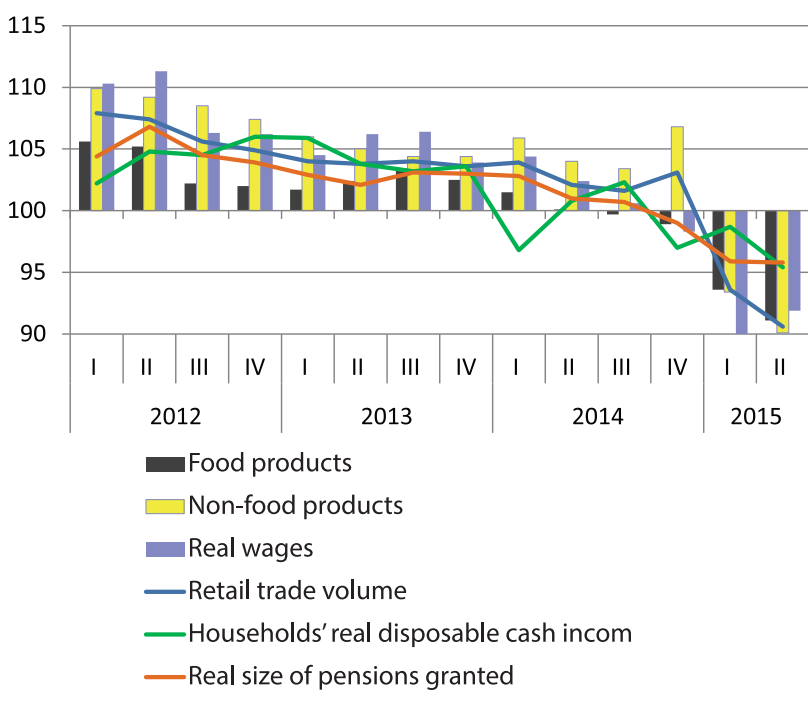

Source: The Rosstat.

Fig. 3. Dynamics of the retail trade volume and households' real income in the 2012-2015 period

as $\%$ of the respective quarter of the previous year

funds from abroad and high interest rates on domestic banks' loans. The volume of credit funds extended by non-financial institutions fell by $17.5 \%$ in nominal terms (as of 1 May 2015) as compared to the same period of the previous year.

Funding of investments in capital assets relies on enterprises' own funds and government financing. Despite a $58 \%$ growth in financial results of enterprises' and entities' activities as compared to January-May 2014 and an increase of 2.1 p.p in the share of the gross profit in GDP as compared to Q1 2014, both enterprises and the banking sector take a rather cautious approach to implementation and funding of investment programs.

A drop in investment demand has been observed since the beginning of 2014 and accompanied by reduction of output of machines and equipment and import of investment goods and building materials. In $\mathrm{H} 12015$, there was a decrease in production of machines and equipment (14.6\%), transport vehicles and equipment (16.7\%) and building materials $(4.2 \%)$ as compared to the previous year. A simultaneous reduction both of production and import of machines and equipment had a highly negative effect on implementation of investment projects on modernization, particularly, in oil and gas production ${ }^{1}$.

From Q3 2014, the extent of building of industrial projects has started to shrink which situation resulted in a drop in the total volume of building jobs. In Q1 2015 and Q2 2015 the volume of building jobs fell

1 OMES No11, 2015 
by $4.7 \%$ and $8.6 \%$, respectively, as compared to the respective period of the previous year and the situation is highly unlikely to improve in $\mathrm{H} 22015$.

From the beginning of 2014, dynamics of domestic demand has been in the area of negative values, but the situation of 2015 has become more complicated due to a simultaneous drop in output of domestic goods and services and import. The pattern of import changed under the impact of a more dramatic drop in deliveries of consumer and investment goods as compared to intermediate consumption goods ${ }^{1}$.

Itemization of GDP by production showed that if in Q1 2015 crisis phenomena affected primarily non-trading sectors of the economy, in Q2 2015 the dynamics of GDP got worse under the impact of decrease in production in industry ${ }^{2}$.

In $\mathrm{H} 12015$, aggravation of slump in industry was justified by a decrease of $4.5 \%$ in output of manufacturing industry, including $1.6 \%$ and $7.4 \%$ in Q1 and $Q 2$, respectively, as compared to the respective period of the previous year. It is to be noted that in Q2 2015 aggravation of slump in production was registered by all the types of activities in the manufacturing industry with the high-tech complex of the engineering industry hit the worst.

In H1 2015 in mining, production stabilized at the level of the previous year.

In $\mathrm{H} 12015$, the total number of the unemployed increased by $6.3 \%$, while the number of the officially registered unemployed, by $5.2 \%$ as compared to the respective indices of 2014. In Q2 2015, the total number of the unemployed increased by $0.22 \mathrm{~m}$ persons as compared to the previous quarter. Despite a drop in economic activities, the level of general unemployment did not deviate from the minimum one throughout the entire period of the index. In H1 2015 , the level of general unemployment amounted to $5.6 \%$ of the gainfully employed population. The need - declared to the state employment services of employers in workers remains below the values of the previous year; the tension coefficient in calculation per 100 declared vacancies amounted to 84 persons against 46.9 persons a year before. Traditionally, in the Russian practice in crisis situations adjustment on the market takes place primarily through reduction of wage amounts, utilization of mechanisms of partial employment and expansion of employment in the informal sector, rather than by way of increasing the number of the unemployed. Growth in the induced partial employment, that is, the number of workers employed part-time or given an unpaid leave

1 OMES No.10, 2015.

2 Economic Development of Russia No.6 (June 2015).

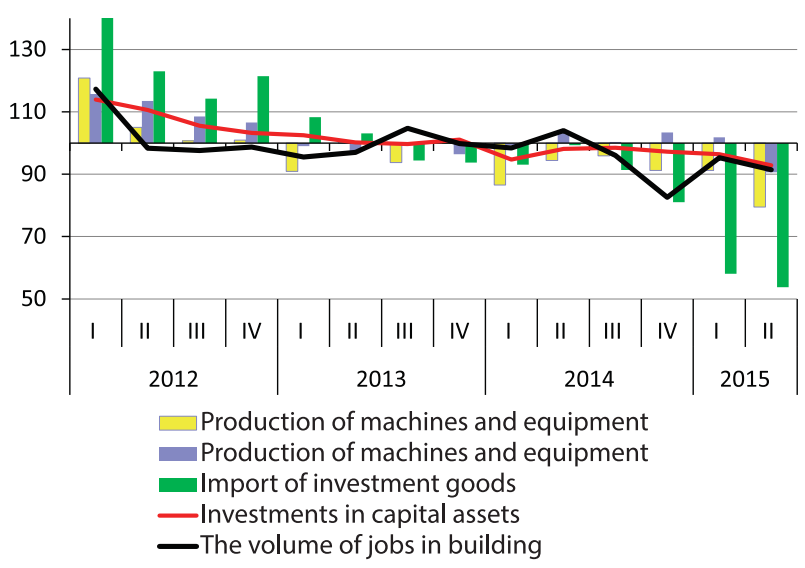

Source: The Rosstat.

Fig. 4. Dynamics of indices of the building and investment complex in the 2012-2015 period

as $\%$ of the respective quarter of the previous year

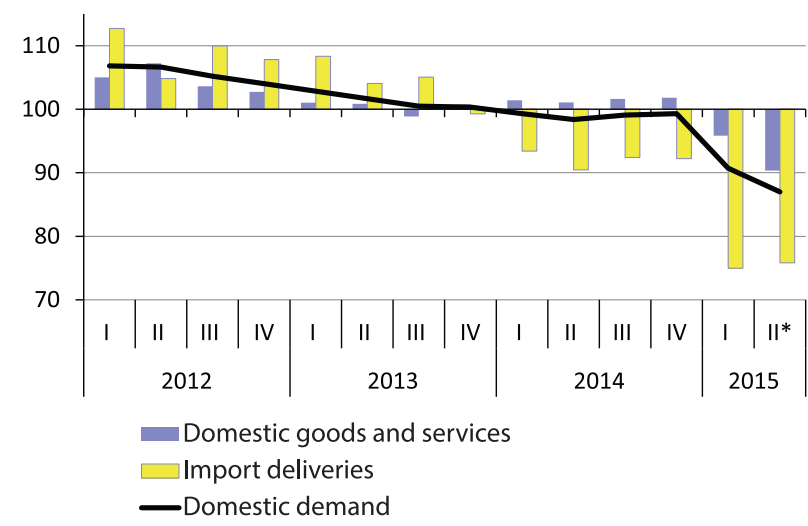

*preliminary estimate.

Source: The Rosstat.

Fig. 5. Dynamics of domestic demand by the component in the 2012-2015 period as \% of the respective quarter of the previous year

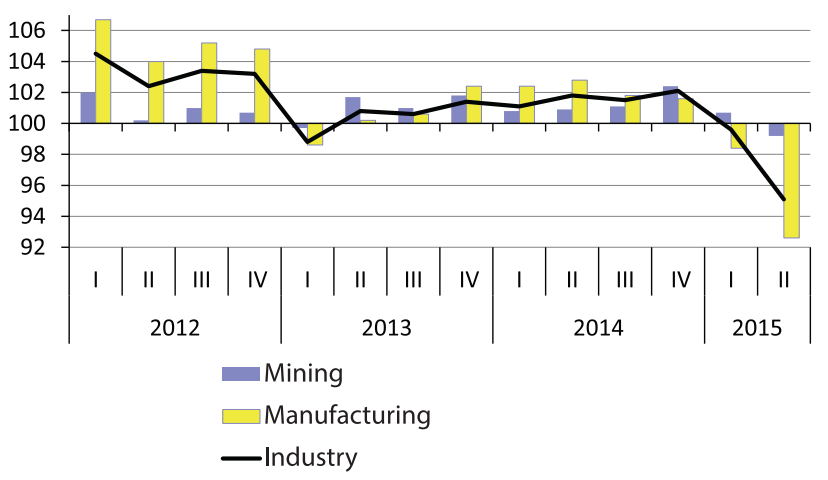

Source: The Rosstat.

Fig. 6. Dynamics of industrial production by the type of economic activities in the 2012-2015 period as $\%$ of the respective quarter of the previous year 
by the administration or by mutual consent between the parties amounted to 335,800 persons (the data provided as of 8 July 2015).

Low investment demand is still the main risk in the short-term and long-term prospects. Problems related to inefficient distribution of inputs are rather painful for the economy. The above is evident not only in the limited mobility of labor resources, but also in weakness of state institutes regulating the market. 